\title{
KRAS mutation as a prognostic factor in ampullary adenocarcinoma: a meta-analysis and review
}

\author{
Bum Jun Kim¹, Hyun Joo Jang ${ }^{2}$, Jung Han Kim ${ }^{1}$, Hyeong Su Kim ${ }^{1}$ Jin Lee ${ }^{2}$ \\ ${ }^{1}$ Division of Hemato-Oncology, Department of Internal Medicine, Kangnam Sacred-Heart Hospital, Hallym University Medical \\ Center, Hallym University College of Medicine, Seoul 07441, Republic of Korea \\ ${ }^{2}$ Division of Gastroenterology, Department of Internal Medicine, Dongtan Sacred-Heart Hospital, Hallym University Medical \\ Center, Hallym University College of Medicine, Hwasung 18450, Republic of Korea
}

Correspondence to: Hyun Joo Jang, email: jhj1229@hallym.or.kr

Jung Han Kim, email: harricil@hotmail.com

Keywords: ampullary adenocarcinoma, KRAS mutation, prognosis, meta-analysis

Received: June 09, 2016

Accepted: July 30, 2016

Published: August 09, 2016

\section{ABSTRACT}

\begin{abstract}
Ampullary adenocarcinoma (A-AC) is a rare malignancy arising from the ampulla of Vater. KRAS mutation is detected in $30-40 \%$ of patients with A-AC, but its clinical implication and prognostic value are not well described. We conducted this metaanalysis to investigate the association between KRAS mutation and prognosis in patients with A-AC. We searched Pubmed, MEDLINE, EMBASE, and the Cochrane Library databases for articles including following terms in their titles, abstracts, or keywords: 'ampullary or periampullary or ampulla of vater', 'cancer or carcinoma', and 'KRAS'. There were five studies with survival data of patients. A total of 388 patients with A-AC from the 5 studies were included in the overall survival (OS) analysis, and 169 patients from 2 studies were eligible for the relapse-free-survival (RFS) analysis. Out of 388 patients, 175 (45\%) had KRAS mutation. There was no association between KRAS mutation and OS (HR = 1.06, 95\% CI: 0.87-1.29, $P=0.58$ ). However, there was a significant correlation between KRAS mutation and worse RFS (HR $=2.74,95 \%$ CI: $1.52-4.92, P=0.0008$ ). In conclusion, this meta-analysis indicates that KRAS mutation is associated with poor RFS, but not with OS in patients with A-AC.
\end{abstract}

\section{INTRODUCTION}

Ampullary adenocarcinoma $(\mathrm{A}-\mathrm{AC})$ is a rare malignancy arising from the ampulla of Vater and accounts for less than $1 \%$ of all gastrointestinal cancers [1]. The ampulla of Vater is a complex region with distinct anatomic structures which include the common bile duct, pancreatic duct, and the duodenum [2]. Due to this complex coalescence of distinct structures, this small area gives rise to a heterogenous group of tumors with different prognosis [3-5].

The histological differentiation [6-8], lymph node involvement $[9,10]$, and vascular invasion [11] have been considered as important prognostic factors for A-AC. However, these parameters were unable to predict the prognosis of A-AC. In addition, the role of molecular and genomic profiles of A-AC as a prognostic factor has not been well investigated.

KRAS gene is included in the mammalian Ras gene family and plays a key role in Ras/mitogen-activated protein kinase signaling [12]. Somatic mutations in KRAS gene act as an early event in the carcinogenesis of human cancers. KRAS mutation is detected at high rate in lung cancer, colorectal cancer (CRC), and pancreatic cancer [13-15]. The presence of mutant KRAS in pancreatic cancer correlated with poor prognosis [16]. KRAS mutation was also associated with a lack of response to EGFR inhibitor in CRC [17]. Mutations in KRAS gene are also found in $30-40 \%$ of patients with A-AC [18-20], but their prognostic value has not been revealed.

We performed this meta-analysis of previous studies to investigate the prognostic value of KRAS mutation in patients with A-AC.

\section{RESULTS}

Results of search and eligible studies

Figure 1 is the flowchart of studies accessed through the review process. The search process yielded 330 studies of which 38 potentially relevant studies were retrieved and 
assessed in detail. After excluding 33 studies (30 studies missed time-dependent survival data and 3 studies were review article), the remaining 5 studies [20-24] fulfilled our eligibility criteria and were included in the metaanalysis. A total of 388 patients were collected from the five studies (Table 1).

\section{KRAS mutation}

The incidence of KRAS mutation was various from $30 \%$ to $67 \%$ among the five studies. Out of 388 patients, $175(45 \%)$ had KRAS mutation. Of 175 patients with mutant KRAS, 134 (76.5\%) had mutation at codon 12 and the most common mutation types were G12D and G12V.

\section{KRAS mutation and overall survival}

We pooled the survival data from the 5 studies to evaluate the association of KRAS mutation and overall survival (OS) in patients with A-AC. Two of 5 studies $[21,24]$ presented hazard ratio (HR) and 95\% confidence interval $(\mathrm{CI})$ in the article. In the remaining 3 studies $[20,22,23]$, we calculated HR and $95 \%$ CI from the available data. As shown in Figure 2A, there was no association between KRAS mutation and OS (HR $=1.06$, 95\% CI: $0.87-1.29, P=0.58)$. There was no statistical heterogeneity among the studies.

\section{KRAS mutation and relapse-free-survival}

Of the 5 studies, only 2 studies [21, 24] reported relapse-free survival (RFS). A total of 169 patients from the 2 studies were included in the RFS analysis. As shown in Figure 2B, there was a significant association between KRAS mutation and worse RFS in patients with A-AC $(\mathrm{HR}=2.74,95 \% \mathrm{CI}: 1.52-4.92, P=0.0008)$.

\section{DISCUSSION}

Because A-ACs are originated from three distinct epithelium (duodenal, biliary, pancreatic) of the ampulla of Vater, it is unclear whether A-ACs have homogenous or heterogenous prognosis. To set up the effective treatment strategy in this type of cancer, it is important to classify the subgroup according to the prognosis. Because of its rarity, however, prognostic factors are not well established.

A number of studies have attempted to classify the disease by identifying prognostic factors. The first approach was to divide the patients as either intestinaltype or pancreatobiliary-type by histology. Several studies found that pancreatobiliary-type showed worse outcome $[6,25,26]$. The second approach was to investigate markers to identify distinct prognostic subgroups of A-ACs. Several markers including intestinal-specific markers, cytokeratin, or microsatellite instability have been evaluated, but the results were limited by small sample size [5, 6, 8, 27-30]. Recently, molecular analysis seems to be a promising approach to identify prognostic factors. Overman et al. segregated A-ACs into two subgroups, intestinal-like subgroup and biliary-like subgroup by gene expression profile, and found that the expression of CK7+/CK20- was dominant in biliary-like subgroup and associated with poor prognosis [7]. In this study, activation of the PI3K-AKT and RAS-RAF-MAPK pathway were also increased in the poor prognostic biliary-like subgroup.

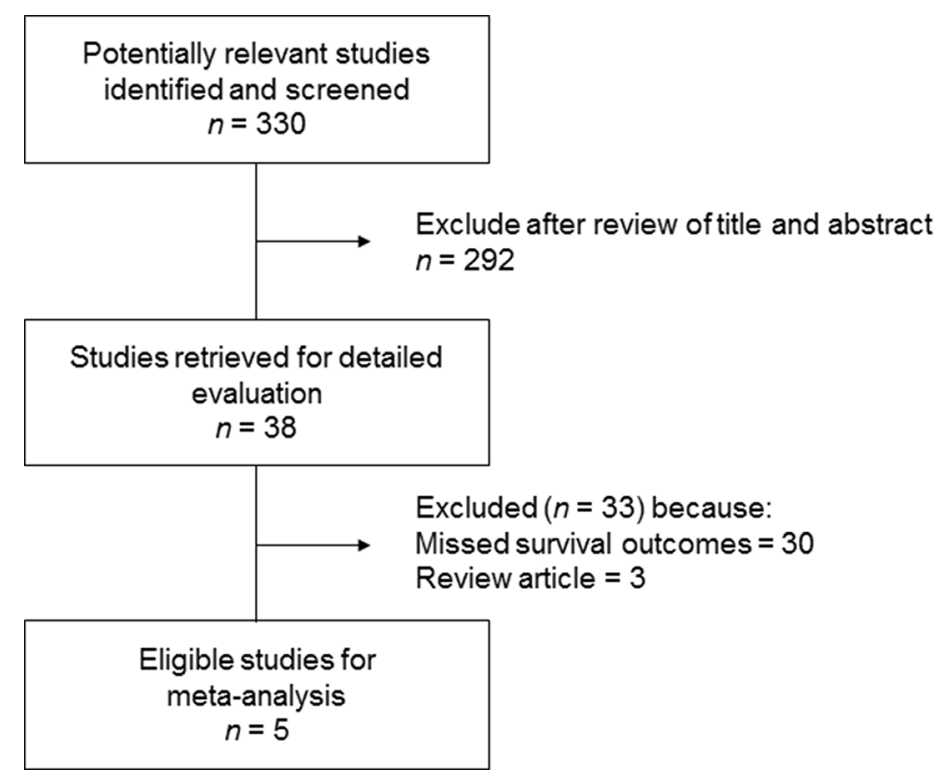

Figure 1: Flow diagram of search process. 
Table 1: Summary of the five studies included in the current meta-analysis

\begin{tabular}{|c|c|c|c|c|c|c|}
\hline Study (ref. no.) & $\begin{array}{l}\text { KRAS } \\
\text { status }\end{array}$ & $n(\%)$ & $\begin{array}{c}\text { RFS } \\
\text { (months) }\end{array}$ & $\begin{array}{l}\text { HR for RFS } \\
(95 \% \mathrm{CI})\end{array}$ & $\begin{array}{c}\text { Median } \\
\text { OS (months) }\end{array}$ & $\begin{array}{c}\text { HR for OS } \\
(95 \% \text { CI })\end{array}$ \\
\hline \multirow[t]{2}{*}{ Howe et al. [20] } & mutant & $34(37 \%)$ & NA & NA & 69.7 & $\begin{array}{c}0.943 \\
(0.68-1.30) \\
P=0.721\end{array}$ \\
\hline & wild & $58(63 \%)$ & NA & & 47.6 & \\
\hline \multirow[t]{2}{*}{ Schultz et al. [21] } & mutant & $72(67 \%)$ & $\begin{array}{c}25.0 \\
\text { (Median) }\end{array}$ & $\begin{array}{c}2.45 \\
(1.19-5.06) \\
P=0.015\end{array}$ & 22.3 & $\begin{array}{c}1.93 \\
(1.12-3.31) \\
P=0.018\end{array}$ \\
\hline & wild & $35(33 \%)$ & Not reached & & 44.7 & \\
\hline \multirow[t]{2}{*}{ Valsangkar et al. [22] } & mutant & $25(33 \%)$ & NA & NA & NA & $\begin{array}{c}1.103 \\
(0.76-1.61) \\
P=0.6087\end{array}$ \\
\hline & wild & $50(67 \%)$ & NA & & NA & \\
\hline \multirow[t]{2}{*}{ Mikhitarian et al. [23] } & mutant & $25(48 \%)$ & NA & NA & 45 & $\begin{array}{c}0.918 \\
(0.65-1.30) \\
P=0.631\end{array}$ \\
\hline & wild & $27(52 \%)$ & NA & & 44 & \\
\hline \multirow[t]{2}{*}{ Kwon et al. [24] } & mutant & $19(31 \%)$ & $\begin{array}{c}29 \\
\text { (Mean) }\end{array}$ & $\begin{array}{c}3.384 \\
(1.25-9.20) \\
P=0.017 \\
\end{array}$ & NA & $\begin{array}{c}1.060 \\
(0.51-2.22) \\
P=0.877\end{array}$ \\
\hline & wild & $43(69 \%)$ & $\begin{array}{c}98 \\
\text { (Mean) }\end{array}$ & & NA & \\
\hline
\end{tabular}

HR, hazard ratio; RFS, relapse-free-survival; OS, overall survival; NA; not available.
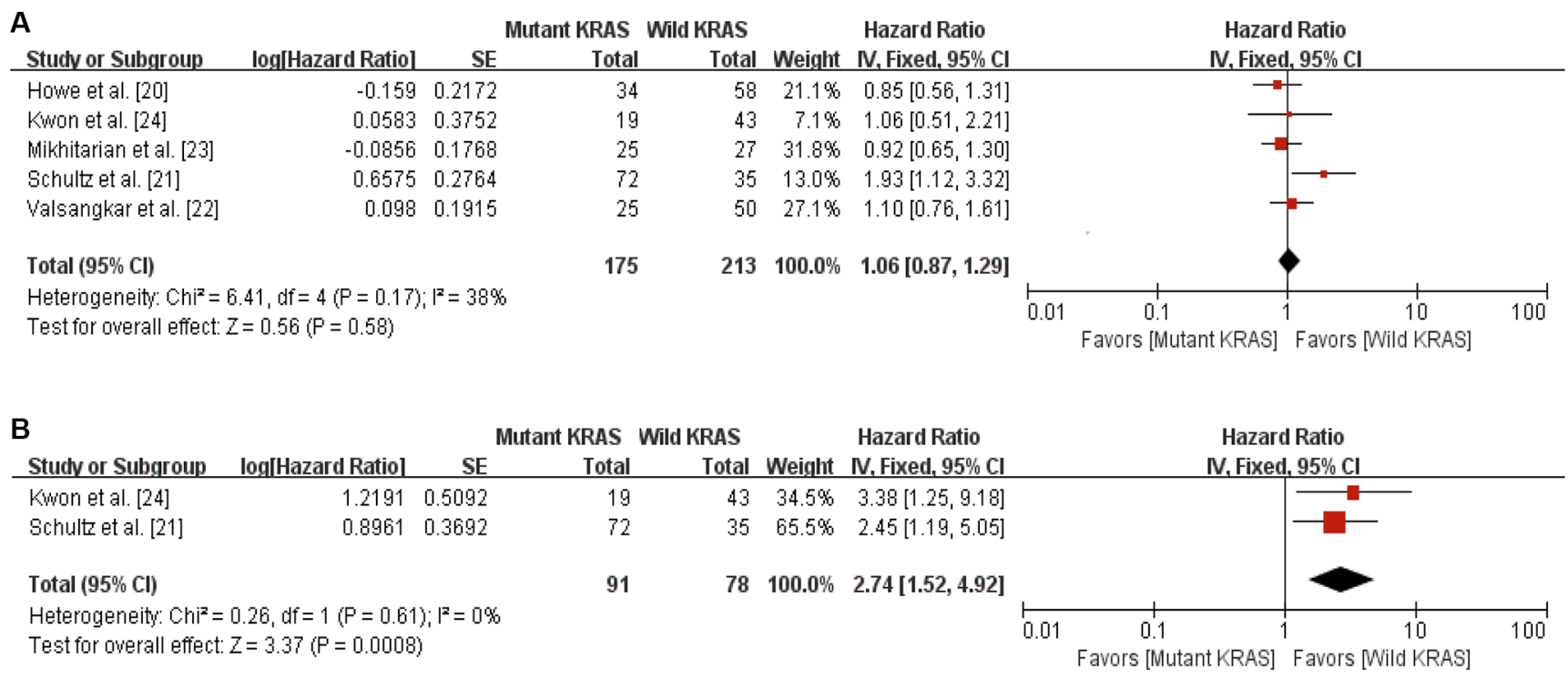

Figure 2: Forest plots for the relation between KRAS mutation and survival outcomes. (A) The relation between KRAS mutation and overall survival. (B) The relation between KRAS mutations and relapse-free survival. 
Mutations in KRAS gene are known to be detected in $30-40 \%$ of patients with A-AC [15-17]. In this meta-analysis, 175 (45\%) out of 388 patients had KRAS mutation. Most KRAS mutation was located at codon 12 and the most common mutation types were G12D and G12V. The association between KRAS mutation and histological subtype was analyzed in three of the five studies and there was no difference in the incidence of KRAS mutation between intestinal-type and pancreatobiliary-type [20, 23, 24]. In one study, KRAS mutation was more frequently detected in poorly differentiated tumors than well-differentiated tumors [24].

The role of KRAS mutation as a prognostic factor is controversial in lung cancer [31-33]. However, KRAS mutation at codon 12 or 13 was associated with worse prognosis in CRC $[34,35]$. In pancreatic cancer, recent meta-analysis demonstrated that KRAS mutation was a potential poor prognostic marker [16]. In patients with $\mathrm{A}-\mathrm{AC}$, however, its prognostic value has not been revealed. Of the five studies included in our meta-analysis, two evaluated the association between KRAS mutation and RFS $[22,24]$. In both studies, KRAS mutation was associated with poor RFS. Our meta-analysis with 169 patients from the two studies demonstrated that there was a significant correlation between KRAS mutation and worse RFS (HR $=2.74,95 \% \mathrm{CI}: 1.52-4.92, P=0.0008)$. In terms of OS, only one study found that KRAS mutation was associated with poor OS [21]. In another study, subgroup analysis showed that patients with KRAS-G12D mutation had poor OS, compared to patients with wildtype KRAS [22]. In our meta-analysis with 388 patients, KRAS mutation was not associated with $\mathrm{OS}(\mathrm{HR}=1.06$, 95\% CI: $0.87-1.29, P=0.58)$. Considering that KRAS mutation related to shorter RFS, however, KRAS mutation might be a potential survival factor in patients with A-AC. Therefore, further studies incorporating detailed subgroup analysis with large population are needed to reveal the relationship between KRAS mutation and survival in patients with A-AC.

This study has several limitations. First, the small number of studies was included in this meta-analysis, with 5 studies for OS analysis and 2 studies for RFS analysis. Second, all the five studies were retrospective review and important clinical information including adjuvant treatment after surgery and palliative chemotherapy which might affect the RFS and OS were not presented. Lastly, because KRAS mutation was not classified into mutational subgroups in most studies, we could not perform subgroup analysis.

In conclusion, this meta-analysis indicates that KRAS mutation is associated with poor RFS, but not with OS in patients with A-AC. Considering that small number patients were included and anti-cancer treatments after surgery could not be analyzed in this study, however, further studies with large population are still needed to reveal the relationship between KRAS mutation and prognosis in patients with A-AC.

\section{MATERIALS AND METHODS}

\section{Searching strategy}

We searched Pubmed, MEDLINE, EMBASE and the Cochrane Library databases (up to May 2016) for articles that included the following medical terms in their titles, abstracts, or keyword lists: 'ampullary or periampullary or ampulla of vater', 'cancer or neoplasm or carcinoma or malignancy', 'KRAS' or 'K-ras', 'prognosis or survival'. All eligible studies were retrieved, and their bibliographies were checked for other relevant publications. Review articles and bibliographies of other relevant studies identified were hand searched to find additional eligible studies. Additionally, we searched all abstracts and virtual meeting presentations from the American Society of Clinical Oncology (ASCO) conferences held between 2007 and 2016 and sought expert opinion to identify relevant but unpublished studies.

\section{Inclusion criteria}

Clinical studies that met the following inclusion criteria were included in the meta-analysis: (i) all patients diagnosed of ampullary cancer were confirmed through histopathologic detection; (ii) KRAS mutational status was accessed by extracting genomic DNA; (iii) the relationship between KRAS mutation and the prognosis of patients with ampullary cancer was investigated by measuring time-dependent end-point, including RFS or OS; (iv) HR for time-dependent end-points were reported or could be calculated from the data provided.

\section{Data extraction}

Data were carefully extracted from all eligible studies by two of the authors (BJK and JHK) independently, and discrepancies were resolved by consensus including a third author (HJJ). The following data were collected from each study: first author's name, year of publication, number of patients, mutation rates for KRAS, time-dependent endpoint including RFS and OS, and HR for time-dependent endpoint.

\section{Statistical analysis}

The association between KRAS mutation and RFS or OS was presented as HR with $95 \%$ CI. The HR and $95 \% \mathrm{CI}$ as relevant effect measures were estimated directly or indirectly from the given data. A fixed effect model was used to calculate the pooled HR estimate. HRs for death were combined using an inverse variance method based on a logarithmic conversion; 95\% CIs were used to determine the standard error (SE) using the formula $\mathrm{SE}=95 \% \mathrm{CI} / 1.96$. The traditional $Q$-test and the $I^{2}$ statistic were used to evaluate heterogeneity. Significant 
heterogeneity was considered to be present for $P<0.05$ in the $Q$ test or for I $>30 \%$. The $Z$-test for overall effect and its two-sided $P$-value were also assessed. RevMan v5.2 software was used to report outcomes.

\section{CONFLICTS OF INTEREST}

Authors declare no conflicts of interest.

\section{GRANT SUPPORT}

This work had no specific funding.

\section{REFERENCES}

1. Benhamiche AM, Jouve JL, Manfredi S, Prost P, Isambert N, Faivre J. Cancer of the ampulla of Vater: results of a 20-year population-based study. Eur J Gastroenterol Hepatol. 2000; 12:75-9.

2. Adsay V, Ohike N, Tajiri T, Kim GE, Krasinskas A, Balci S, Bagci P, Basturk O, Bandyopadhyay S, Jang K-T, Kooby DA, Maithel SK, Sarmiento J, et al. Ampullary region carcinomas: definition and site specific classification with delineation of four clinicopathologically and prognostically distinct subsets in an analysis of 249 cases. Am J Surg Pathol. 2012; 36:1592-608.

3. Balachandran P, Sikora SS, Kapoor S, Krishnani N, Kumar A, Saxena R, Kapoor VK. Long-term survival and recurrence patterns in ampullary cancer. Pancreas. 2006; 32:390-5.

4. Kayahara M, Ohta T. Gross appearance of the ampullary tumor predicts lymph node metastasis and outcome. Dig Surg. 2010; 27:127-31.

5. Roh Y-H, Kim Y-H, Lee H-W, Kim S-J, Roh M-S, Jeong J-S, Jung G-J. The clinicopathologic and immunohistochemical characteristics of ampulla of Vater carcinoma: the intestinal type is associated with a better prognosis. Hepatogastroenterology. 2007; 54:1641-4.

6. Kohler I, Jacob D, Budzies J, Lehmann A, Weichert W, Schulz S, Neuhaus P, Röcken C. Phenotypic and genotypic characterization of carcinomas of the papilla of Vater has prognostic and putative therapeutic implications. Am J Clin Pathol. 2011; 135:202-11.

7. Overman MJ, Zhang J, Kopetz S, Davies M, Jiang Z-Q, Zhi-Qin J, Stemke-Hale K, Rümmele P, Pilarsky C, Grützmann R, Hamilton S, Hwang R, Abbruzzese JL, et al. Gene expression profiling of ampullary carcinomas classifies ampullary carcinomas into biliary-like and intestinal-like subtypes that are prognostic of outcome. PloS One. 2013; 8:e65144.

8. Zhou H, Schaefer N, Wolff M, Fischer H-P. Carcinoma of the ampulla of Vater: comparative histologic/ immunohistochemical classification and follow-up. Am J Surg Pathol. 2004; 28:875-82.
9. Lee JH, Lee KG, Ha TK, Jun YJ, Paik SS, Park HK, Lee KS. Pattern analysis of lymph node metastasis and the prognostic importance of number of metastatic nodes in ampullary adenocarcinoma. Am Surg. 2011; 77:322-9.

10. de Paiva Haddad LB, Patzina RA, Penteado S, Montagnini AL, da Cunha JEM, Machado MCC, Jukemura J. Lymph node involvement and not the histophatologic subtype is correlated with outcome after resection of adenocarcinoma of the ampulla of vater. $\mathrm{J}$ Gastrointest Surg Off J Soc Surg Aliment Tract. 2010; 14:719-28.

11. Todoroki T, Koike N, Morishita Y, Kawamoto T, Ohkohchi N, Shoda J, Fukuda Y, Takahashi H. Patterns and predictors of failure after curative resections of carcinoma of the ampulla of Vater. Ann Surg Oncol. 2003; 10:1176-83.

12. Malumbres M, Barbacid M. RAS oncogenes: the first 30 years. Nat Rev Cancer. 2003; 3:459-65.

13. Burmer GC, Loeb LA. Mutations in the KRAS2 oncogene during progressive stages of human colon carcinoma. Proc Natl Acad Sci U S A. 1989; 86:2403-7.

14. Almoguera C, Shibata D, Forrester K, Martin J, Arnheim N, Perucho M. Most human carcinomas of the exocrine pancreas contain mutant c-K-ras genes. Cell. 1988; 53:549-54.

15. Tam IYS, Chung LP, Suen WS, Wang E, Wong MCM, Ho KK, Lam WK, Chiu SW, Girard L, Minna JD, Gazdar AF, Wong MP. Distinct Epidermal Growth Factor Receptor and KRAS Mutation Patterns in Non-Small Cell Lung Cancer Patients with Different Tobacco Exposure and Clinicopathologic Features. Am Assoc Cancer Res. 2006; 12:1647-53.

16. Tao L-Y, Zhang L-F, Xiu D-R, Yuan C-H, Ma Z-L, Jiang B. Prognostic significance of K-ras mutations in pancreatic cancer: a meta-analysis. World J Surg Oncol. 2016; 14:146-53.

17. Allegra CJ, Jessup JM, Somerfield MR, Hamilton SR, Hammond EH, Hayes DF, McAllister PK, Morton RF, Schilsky RL. American Society of Clinical Oncology provisional clinical opinion: testing for KRAS gene mutations in patients with metastatic colorectal carcinoma to predict response to anti-epidermal growth factor receptor monoclonal antibody therapy. J Clin Oncol Off J Am Soc Clin Oncol. 2009; 27:2091-6.

18. Schönleben F, Qiu W, Allendorf JD, Chabot JA, Remotti HE, Su GH. Molecular analysis of PIK3CA, BRAF, and RAS oncogenes in periampullary and ampullary adenomas and carcinomas. J Gastrointest Surg Off J Soc Surg Aliment Tract. 2009; 13:1510-6.

19. Matsubayashi H, Watanabe H, Yamaguchi T, Ajioka Y, Nishikura K, Kijima H, Saito T. Differences in mucus and K-ras mutation in relation to phenotypes of tumors of the papilla of vater. Cancer. 1999; 86:596-607.

20. Howe JR, Klimstra DS, Cordon-Cardo C, Paty PB, Park PY, Brennan MF. K-ras mutation in adenomas and carcinomas of the ampulla of vater. Clin Cancer Res Off J Am Assoc Cancer Res. 1997; 3:129-33. 
21. Schultz NA, Roslind A, Christensen IJ, Horn T, Høgdall E, Pedersen LN, Kruhøffer M, Burcharth F, Wøjdemann M, Johansen JS. Frequencies and prognostic role of KRAS and BRAF mutations in patients with localized pancreatic and ampullary adenocarcinomas. Pancreas. 2012; 41:759-66.

22. Valsangkar NP, Ingkakul T, Correa-Gallego C, MinoKenudson M, Masia R, Lillemoe KD, Fernández-del Castillo C, Warshaw AL, Liss AS, Thayer SP. Survival in ampullary cancer: potential role of different KRAS mutations. Surgery. 2015; 157:260-8.

23. Mikhitarian K, Pollen M, Zhao Z, Shyr Y, Merchant N, Parikh A, Revetta F, Washington K, Vnencak-Jones C, Shi C. Epidermal Growth Factor Receptor Signaling Pathway is Frequently Altered in Ampullary Carcinoma at Protein and Genetic Levels. Mod Pathol Off J U S Can Acad Pathol Inc. 2014; 27:665-74.

24. Kwon MJ, Kim JW, Jung JP, Cho JW, Nam ES, Cho SJ, Kim JS, Park H-R, Min SK, Seo J, Min K-W, Kim DH, Jeon JY. Low incidence of KRAS, BRAF, and PIK3CA mutations in adenocarcinomas of the ampulla of Vater and their prognostic value. Hum Pathol. 2016; 50:90-100.

25. Westgaard A, Tafjord S, Farstad IN, Cvancarova M, Eide TJ, Mathisen O, Clausen OPF, Gladhaug IP. Pancreatobiliary versus intestinal histologic type of differentiation is an independent prognostic factor in resected periampullary adenocarcinoma. BMC Cancer. 2008; 8:170-80.

26. Neoptolemos JP, Moore MJ, Cox TF, Valle JW, Palmer DH, McDonald AC, Carter R, Tebbutt NC, Dervenis C, Smith D, Glimelius B, Charnley RM, Lacaine F, et al. Effect of adjuvant chemotherapy with fluorouracil plus folinic acid or gemcitabine vs observation on survival in patients with resected periampullary adenocarcinoma: the ESPAC-3 periampullary cancer randomized trial. JAMA. 2012; 308:147-56.

27. Ruemmele P, Dietmaier W, Terracciano L, Tornillo L, Bataille F, Kaiser A, Wuensch P-H, Heinmoeller E, Homayounfar K, Luettges J, Kloeppel G, Sessa F, Edmonston TB, et al. Histopathologic features and microsatellite instability of cancers of the papilla of vater and their precursor lesions. Am J Surg Pathol. 2009; 33:691-704.

28. Hansel DE, Maitra A, Lin JW, Goggins M, Argani P, Yeo CJ, Piantadosi S, Leach SD, Biankin AV. Expression of the caudal-type homeodomain transcription factors CDX $1 / 2$ and outcome in carcinomas of the ampulla of Vater. $J$ Clin Oncol Off J Am Soc Clin Oncol. 2005; 23:1811-8.

29. Sessa F, Furlan D, Zampatti C, Carnevali I, Franzi F, Capella C. Prognostic factors for ampullary adenocarcinomas: tumor stage, tumor histology, tumor location, immunohistochemistry and microsatellite instability. Virchows Arch Int J Pathol. 2007; 451:649-57.

30. Vincenzi B, Santini D, Perrone G, Russo A, Adamo V, Rizzo S, Castri F, Antinori A, Alloni R, Crucitti PF, Morini S, Rabitti C, Vecchio FM, et al. Promyelocytic leukemia (PML) gene expression is a prognostic factor in ampullary cancer patients. Ann Oncol Off J Eur Soc Med Oncol ESMO. 2009; 20:78-83.

31. Mascaux $C$, Iannino $N$, Martin $B$, Paesmans $M$, Berghmans T, Dusart M, Haller A, Lothaire P, Meert A-P, Noel S, Lafitte J-J, Sculier J-P. The role of RAS oncogene in survival of patients with lung cancer: a systematic review of the literature with meta-analysis. Br J Cancer. 2005; 92:131-9.

32. Camps C, Jantus-Lewintre E, Cabrera A, Blasco A, Sanmartín E, Gallach S, Caballero C, del Pozo N, Rosell R, Guijarro R, Sirera R. The identification of KRAS mutations at codon 12 in plasma DNA is not a prognostic factor in advanced non-small cell lung cancer patients. Lung Cancer Amst Neth. 2011; 72:365-9.

33. Loriot Y, Mordant P, Deutsch E, Olaussen KA, Soria J-C. Are RAS mutations predictive markers of resistance to standard chemotherapy? Nat Rev Clin Oncol. 2009; 6:528-34.

34. Bazan V, Migliavacca M, Zanna I, Tubiolo C, Grassi N, Latteri MA, La Farina M, Albanese I, Dardanoni G, Salerno S, Tomasino RM, Labianca R, Gebbia N, et al. Specific codon 13 K-ras mutations are predictive of clinical outcome in colorectal cancer patients, whereas codon 12 K-ras mutations are associated with mucinous histotype. Ann Oncol Off J Eur Soc Med Oncol ESMO. 2002; 13:1438-46.

35. Andreyev HJ, Norman AR, Cunningham D, Oates J, Dix BR, Iacopetta BJ, Young J, Walsh T, Ward R, Hawkins N, Beranek M, Jandik P, Benamouzig R, et al. Kirsten ras mutations in patients with colorectal cancer: the "RASCAL II” study. Br J Cancer. 2001; 85:692-6. 